\title{
Educación, laicismo y socialismo en la Argentina: las organizaciones de maestros y profesores entre 1955 у $1983 *$
}

\section{LaUra Graciela Rodríguez}

\begin{abstract}
Profesora del Consejo Nacional de Investigaciones Científicas y Tecnológicas - CONICET (Argentina) y de la Universidad Nacional de la Plata (Argentina). Correo electrónico: lau.g.rodrig@gmail.com. La autora es Licenciada en Historia de la Universidad Nacional de Misiones (Argentina), magíster en Ciencias Sociales con mención en Sociología de la Facultad Latinoamericana de Ciencias Sociales/FLACSO (Argentina) y doctora en Antropología Social de la Universidad Nacional de Misiones (Argentina). Entre sus publicaciones recientes tenemos: "Iglesia y educación en la Argentina durante la segunda mitad del siglo XX" en Cadernos de Histórica da Educacao, Vol. 14 (2015) y "Funcionarios y políticas educativas en Argentina (1976-1983)" en Cuadernos Chilenos de Historia de la Educación No. 4 (2015). Entre sus temas de interés están historia de la educación, historia política y social de las dictaduras, historia y sociología del Estado y los funcionarios.
\end{abstract}

Recibido: 8 de agosto de 2015

Aprobado: 17 de mayo de 2016

Modificado: 30 de mayo de 2016

Artículo de investigación científica

DOI: http://dx.doi.org/10.15648/hc.30.2016.7

\footnotetext{
* $\quad$ Este artículo forma parte del proyecto: "Intelectuales, funcionarios y políticas educativas en el Ministerio de Educación (1955-1983)" financiado por el Consejo Nacional de Investigaciones Científicas y Tecnológicas (Argentina).

Esta publicación está bajo una licencia Creative Commons Reconocimiento-NoComercial 4.0
} 
Educación, laicismo y socialismo en la Argentina: las organizaciones de maestros y profesores entre 1955 y 1983

\title{
Resumen
}

En este artículo analizaremos las características del movimiento laicista en la Argentina desde 1955 hasta 1983. Estuvo integrado por un grupo de maestros normalistas afiliados al Partido Socialista que tenían a Domingo Faustino Sarmiento como su principal referente. Observaremos en qué tipo de organizaciones estuvieron -especialmente la Confederación Argentina de Maestros y Profesores y la Liga Argentina de Cultura Laica-, cuál era el modelo de educación laica que proponían, quiénes fueron sus principales dirigentes, en qué redes nacionales e internacionales participaban y cuál fue el rol que cumplieron estos dos grupos en el proceso de laicización.

Palabras clave: laicismo, Argentina, maestros, socialismo.

Education, secularism and socialism in Argentina: the organizations of teachers and professors between 1955 and 1983

\begin{abstract}
This article analyzes the secularist movement characteristics in Argentina from 1955 to 1983. It was composed by a group of normal school teachers affiliated with the Socialist Party, which had Domingo Faustino Sarmiento as its main reference. Based on the study of La Vanguardia and Consudec newspapers, among others, it is observe in what type of organizations they were -especially the Argentinean Confederation of Professors and teachers and the Secular Culture Argentina League- What was the model of secular education proposed, who were their main leaders, in what national and international networks they participated and what was the role played by these two groups in the process of secularization.
\end{abstract}

Key words: secularist, Argentina, teachers, socialism.

Educação, laicismo e socialismo na Argentina: as organizações de maestros e professores entre 1955 e 1983

\section{Resumo}

Neste artigo analisaremos as características do movimento laicista na Argentina desde 
1955 até 1983. Esteve integrado por um grupo de mestres normalistas filiados ao Partido Socialista que tinham a Domingo Faustino Sarmiento como seu principal referente. Em base ao estudo dos jornais A Vanguardia e Consudec, entre outros, observaremos em que tipo de organizações estiveram -especialmente a Confederação Argentina de Maestres e Professores e a liga Argentina de Cultura Laica-, qual era o modelo de educação laica que propunham, quem foram seus principais dirigentes, em que redes nacionais e internacionais participavam e qual foi o papel que cumpriram estes dois grupos no processo de laicización.

Palavras-chave: laicismo, Argentina, mestres, socialismo.

\section{Éducation, laïcisme et socialisme en Argentine: les organisations d'instituteurs et professeurs entre 1955 et 1983}

\section{Résumé}

Dans cet article, on analyse les caractéristiques du mouvement laïciste en Argentine depuis 1955 jusqu'en 1983. Celui-ci fut intégré par un groupe d'enseignants normalistes affiliés au Parti Socialiste qui avaient Domingo Faustino Sarmiento comme leur principal référent. À partir de l'étude des journaux La Vanguardia et Consudec, entre autres, on examine dans quelle sorte d'organisations militèrent-ils, ces enseignants -notamment la Confédération Argentine d'Enseignants et Professeurs et la Ligue Argentine de Culture Laïque-, quel était le modèle d'éducation laïque qu'ils proposaient, qui furent leurs principaux dirigeants, à quels réseaux nationaux et internationaux participaient-ils et quel fut le rôle que ces deux groupes accomplirent dans le processus de laïcisation.

Mots clés: laïcisme, Argentine, enseignants, socialisme.

En este artículo analizaremos las características del movimiento laicista en la Argentina desde 1955 hasta $1983^{1}$. Con base en nuestras investigaciones sobre el Consejo Superior de Educación Católica y su órgano de difusión, el periódico Consudec, hemos identificado que los representantes de la Iglesia polemizaron en toda esta etapa con los referentes de dos organizacio-

1 Agradezco la valiosa lectura de este trabajo a Flavia Fiorucci, Ricardo Martínez Mazzola, Silvana G. Ferreyra y a los evaluadores anónimos. Los errores y omisiones son de mi entera responsabilidad. 
nes que calificaban de "laicistas" y "ateas": la Confederación Argentina de Maestros y Profesores (CAMYP) y la Liga Argentina de Cultura Laica (LACL), cuyas proclamas y pedidos se publicaban en el periódico oficial del Partido Socialista Democrático (PSD), La Vanguardia (1962-1983). A partir de este hallazgo, decidimos poner el foco en ellas para conocer, por un lado, cuál era el modelo de educación laica que defendían la CAMYP y la LACL, quiénes eran sus dirigentes y en qué se diferenciaba cada organización. Por el otro, qué rol cumplieron estos dos grupos en el proceso de laicización ${ }^{2}$.

Pretendemos mostrar, en primer término, que los responsables de la CAMYP y la LACL creían que el modelo laicista debía ser garantizado por el Estado, quien debía asegurarse el nombramiento de funcionarios afines con el laicismo; disminuir o eliminar los aportes al sector privado (mayoritariamente católico), y ejercer el monopolio de la supervisión de la educación privada, entre otras cosas. Sus líderes más importantes -Américo Ghioldi, José S. Campobassi, Alfredo P. Bravo y Atilio Torrassa- eran maestros y profesores varones egresados de las Escuelas Normales nacionales entre las décadas de 1910 y 1920 que simpatizaban o eran afiliados al Partido Socialista. En relación a sus diferencias, observaremos que los referentes de cada grupo tenían distintas nociones acerca de cómo intervenir en la esfera pública. Los primeros se constituyeron en un gremio docente, masivo y heterogéneo, cuyas acciones se concentraron en reclamar mejores condiciones laborales. Los segundos aspiraban a consolidarse como un movimiento de intelectuales vinculado orgánicamente al PSD, que privilegiaba la palabra escrita como forma de actuación. Veremos que publicaron numerosos libros concentrados en tres temáticas: el laicismo;

2 Siguiendo a Roberto Di Stefano, entendemos por laicización a la política estatal de absorción de instituciones y funciones que tuvo lugar en los países católicos a partir de la década de 1870, cuando la expresión se puso en boga para aludir a ciertas medidas tomadas en el marco de la Tercera República Francesa. La laicización, como sustracción a la autoridad religiosa de instituciones y de funciones que pasaban a la órbita del Estado, constituyó entonces un aspecto del proceso mayor y más complejo, que fue el de la secularización. Se entiende por secularización el proceso de pérdida de la capacidad normativa de la religión y el ajuste de los fenómenos que se producen en planos que empiezan a diferenciarse de ella: la política, la economía, la sociedad, la cultura, la ciencia. Decir que una sociedad se ha secularizado "implica que sus comportamientos han ganado autonomía respecto de la autoridad religiosa". Roberto Di Stefano, "Por una historia de la secularización y de la laicidad en la Argentina", Quinto Sol, Vol. 15, No. 1, (2011):4 
la defensa de las figuras de la historiografía liberal cuyo máximo exponente era Domingo Fasutino Sarmiento, y el problema de límites con Chile ${ }^{3}$.

En segundo lugar, señalaremos que la CAMYP y la LACL cumplieron un papel protagónico en esos años denunciando el avance de la Iglesia en la educación, aunque resultaron relativamente eficaces como grupo de presión al poder político. La realidad demostró que la mayoría de los encargados del área educativa nombrados entre 1955 y 1983 fueron afines a la Iglesia y los católicos lograron la aprobación de importantes normas que, entre otras cosas, les otorgaron mayor autonomía a las escuelas privadas. Sin embargo, la Iglesia no pudo -a pesar de intentarlo en dos oportunidades- derogar la Ley 1420; tuvo problemas con el financiamiento estatal y si bien el número de escuelas privadas católicas y la matrícula crecieron en general, su participación porcentual en relación al sistema público no se modificó sustancialmente. En suma, tanto laicistas como católicos contaron en su haber avances y retrocesos, más allá de las acusaciones que unos y otros hacían. De todos modos, visto en el largo plazo, los laicistas intuyeron tempranamente que estaban frente a una tendencia que se profundizaría. Efectivamente, en la década de 1990 se dio en la Argentina el fenómeno de la consolidación del sistema privado en detrimento del público, en virtud del argumento que la escuela privada era "más barata" para el Estado.

Ahora bien, este artículo está estructurado cronológicamente en cuatro apartados: en el primero resumiremos brevemente lo sucedido desde la sanción de la Ley de Educación N 1420 en 1884 hasta el fin del gobierno del general Perón en 1955; el segundo va desde el golpe de Estado de 1955 y finaliza con el derrocamiento del presidente Arturo Illia (1963) en 1966; el tercero abarca el periodo de la quinta dictadura (1966-1973) encabezada por el general Juan Carlos Onganía y sigue con la etapa democrática del tercer gobierno peronista (1973-1976). El último apartado plantea lo ocurrido durante los años de la última dictadura (1976-1983).

3 Domingo F. Sarmiento (1811-1888, n. en San Juan) fue político, escritor, docente, periodista, militar y estadista. Entre los numerosos cargos públicos que ocupó estuvieron el de gobernador de la provincia de San Juan, presidente de la Confederación Argentina entre 1868 y 1874, director general de escuelas por la provincia de Buenos Aires (1875), senador por la provincia de San Juan y ministro del interior (1879). Se destacó, entre otras cosas, por su defensa del sistema público de enseñanza. 


\section{Católicos, liberales y Peronistas (1884-1955)}

En 1884 se sancionó la Ley de Educación Nº 1420 donde se establecía que la enseñanza sería laica, o más precisamente, que podía impartirse religión fuera del horario de clase (Art. 8). La norma tenía vigencia solamente en la Capital Federal y en diez Territorios Nacionales. Estos últimos representaban alrededor de la mitad de la superficie total; se caracterizaban por tener una importante población aborigen y una presencia creciente de las órdenes religiosas que se ocuparon de la educación y de la "conversión a los indígenas al catolicismo" de acuerdo al artículo 64 (inciso 15) de la Constitución Nacional (1853) ${ }^{4}$. Los católicos solían compartir con los liberales los mismos círculos de sociabilidad y gran parte de la elite no cuestionaba el carácter cristiano de la "civilización" que debía implantarse. Ambos estuvieron de acuerdo en aprobar programas que establecían contenidos tales como "Deberes para con Dios".

En este sentido, la separación formal de la Iglesia y del Estado que se estableció en México (1857), Brasil (1889), Francia (1905), Uruguay (1919) o Chile (1925), nunca pudo realizarse en Argentina ${ }^{6}$. Es decir, en momentos de mayor auge del Liberalismo, el Estado argentino participó del proceso de conformación y consolidación de la Iglesia nacional y no fue en absoluto su enemigo ${ }^{7}$. Asimismo, en comparación con otros países, el anticlericalismo no revistió el mismo tono agresivo contra la Iglesia ${ }^{8}$.

4 Para conocer la obra de los franciscanos en el Nordeste del país y de los salesianos en el sur, ver Gabriela Dalla- Corte Caballero, Mocovíes, franciscanos y colonos en la zona chaqueña de Santa Fe (1850-2011) (Rosario, Prohistoria, 2012); María Andrea Nicoletti, "La congregación salesiana en la Patagonia: civilizar, educar y evangelizar a los indígenas (1880-1934)", Estudios interdisciplinarios de América Latina y el Caribe, Vol. 15, (2004): 71-92.

5 Lucía Lionetti, "La educación pública: escenario de conflictos y acuerdos entre católicos y liberales en la Argentina de fines del siglo XIX y comienzos del XX", Anuario de Estudios Americanos, Vol. 63, (2006):77-106. Sobre el contexto más general ver, entre otros, Loris Zanatta, Del Estado liberal a la nación católica (Bernal: UNQ, 1996).

6 Roberto Di Stefano, "Por una historia".

7 Di Stefano habla del "pacto laico" que se dio entre 1880 y 1920, que nació de la toma de conciencia, por parte de un sector de las elites dirigentes "laicas" y de las jerarquías eclesiásticas, de que ninguno de los dos poderes podía prescindir del otro. Roberto Di Stefano, "El pacto laico argentino (1880-1920)", Polbis, No 8, (2011): 80-89, disponible en http://historiapolitica.com/datos/boletin/ polhis8_DiSTEFANO.pdf [consultado 3 de marzo 2012].

8 Por ejemplo, como en México. Ver Miranda Lida, "La Iglesia Católica en las más recientes historiografías de México y Argentina. Religión, modernidad y secularización”, Historia Mexicana, N 
Después de 1884 en las provincias se fueron sancionando nuevas leyes de educación que terminaron conformando un heterogéneo y cambiante mapa en relación a la enseñanza de la educación católica ${ }^{9}$. Es decir, en importantes regiones del país, el proceso de laicización fue avanzando lentamente, y convivió con sectores católicos que se resistieron a los cambios. Aún así, un importante referente de la Iglesia no dudaba en afirmar que la Ley 1420, a causa de su artículo octavo, no solo era una norma que estaba "en contradicción con toda la tradición argentina, desde 1536 hasta 1884", sino que era una ley "antiargentina, anticonstitucional, anticatólica, antipedagógica, antidemocrática, antifilosófica y antihumana" ${ }^{10}$. En suma, como señala una especialista, la tesis de la secularización "será empuñada como un arma, sin importar si los hechos históricos y la realidad social concordaban o no con la teoría" ${ }^{11}$.

Respecto a la educación privada -que en esos años era mayoritariamente católica- se había aprobado en 1878 la Ley 934 de "Libertad de Enseñanza" que establecía un sistema a través del cual los establecimientos privados de enseñanza media y provinciales, podían "incorporarse" a la enseñanza oficial si tenían los mismos planes de estudios, lo que posibilitaba a sus alumnos rendir un examen, ser considerado alumno de un colegio nacional y acceder a la universidad.

Desde las primeras décadas del siglo XX, la Iglesia se dedicó a fortalecer su actividad religiosa y a ocuparse de manera especial por la cuestión social. Se alió a las Fuerzas Armadas y entre ambas construyeron el mito de

4, (2007): 1339-1426. Sobre el proceso mexicano, ver, entre otros, Adelina Arredondo y Roberto González Villarreal, "De la secularización a la laicidad educativa en México", Historia de la educación. Anuario SAHE, Vol. 15, № 2, (2014): 140-167. Para conocer lo ocurrido en Europa, ver, por ejemplo, Joaquim Pintassilgo, (coord.) Laicidades, Religioes e Educaçao na Europa do Sul no Século XX (Lisboa: FCT, 2013). Para el caso argentino ver también Roberto Di Stefano, Ovejas negras. Historia de los anticlericales argentinos (Buenos Aires: Sudamericana, 2010); Fortunato Mallimaci, El mito de la Argentina laica (Buenos Aires: Capital Intelectual, 2015); Germán Torres, "Iglesia católica, educación y laicidad en la historia argentina”, História da Educação, № 18 (44): 165-185.

9 Guillermo Furlong, Tradición religiosa en la escuela argentina (Buenos Aires: Ed. Theoria, 1957), 119. Sobre el caso de Santa Fe, ver Diego Mauro, "Procesos de laicización en Santa Fe (Argentina): 18601900. Consideraciones sobre la Argentina liberal y laica”, Revista de Indias, No 261, (2014): 539-560.

10 Guillermo Furlong, Tradición religiosa, 90.

11 Miranda Lida, "La Iglesia Católica": 1412. 
la "nación católica" que se cristalizó alrededor de 1930 12. A tono con el escenario más general, en 1931 fundó Acción Católica, en 1936 la Federación de Maestros y Profesores Católicos, y en 1939 el Episcopado creó el Consejo Superior de Educación Católica o CONSUDEC (el primer intento había sido en 1925). Los esfuerzos vertidos resultaron exitosos y logró que importantes provincias como Buenos Aires, Santa Fe y Catamarca (re) implantaran la enseñanza católica en las escuelas públicas. Luego extendió la "reconquista" de la escuela a nivel nacional en 1943, con el segundo golpe de Estado ${ }^{13}$.

Después de ganar las elecciones presidenciales en 1946, Juan Domingo Perón ratificó esta alianza con la Iglesia y durante su primera presidencia aprobó la Ley 13047/47 llamada Estatuto del Docente Privado ${ }^{14}$. Allí se disponía que el Estado contribuyese con el ciento por ciento de los sueldos del personal de las escuelas que eran totalmente gratuitas y hasta un mínimo del 20 \% para aquellas que cobraban al alumnado. En 1954 Perón decidió, por distintas razones, enfrentarse con la Iglesia y al año siguiente fue víctima de un golpe de Estado organizado, entre otros, por un sector de las Fuerzas Armadas y la Iglesia Católica.

\section{Los Socialistas fRente al AVANCE CATÓlico (1955-1966): "Nueva Y VIOLENTA AGRESIÓN HACIA LA ESCUELA PÚBLICA"}

La mayoría de los dirigentes del Partido Socialista (PS) declararon su apoyo público al golpe de 1955. El PS había sido fundado por el médico Juan B. Justo en 1896, siendo el periódico La Vanguardia (1894) su órgano oficial. Entre sus principios estaba defender la instrucción laica y obligatoria. Justo, junto con otros referentes como el doctor Nicolás Repetto, tuvieron una actuación destacada en tanto legisladores y propusieron en varias ocasiones la separación de la Iglesia y el Estado, sin éxito. Hubo varios movimientos de docentes socialistas que fundaron, por ejemplo, la

12 Roberto Di Stefano y Loris Zanatta, Historia de la Iglesia Argentina. Desde la Conquista hasta fines del siglo XX (Buenos Aires: Mondadori, 2000).

13 Roberto Di Stefano y Loris Zanatta, Historia de la Iglesia.

14 Sobre la relación de Perón con la Iglesia, ver Lila Caimari, Perón y la Iglesia Católica. Religión, Estado y Sociedad en la Argentina. 1943-1955 (Buenos Aires: Ariel, 1995). 
Confederación de Maestros en 1916 ${ }^{15}$. Admiraban a Domingo F. Sarmiento, promovieron bibliotecas populares y buscaron generar vínculos participativos con los alumnos y sus padres combatiendo el autoritarismo de los funcionarios nacionales ${ }^{16}$. Uno de los integrantes de la Confederación era Américo Ghioldi, maestro y profesor egresado de la Escuela Normal Mariano Acosta. En los años de 1940, la aparición del peronismo puso en crisis al Partido Socialista y Ghioldi y Repetto acusaron a Perón de ser "fascista" y "tirano"17.

Tras el golpe de 1955, autodenominado "Revolución Libertadora" (19551958) al mando del general Eduardo Lonardi primero, y Pedro Eugenio Aramburu después, la Iglesia logró que se nombrara en el área educativa a funcionarios propios y avanzó todo lo que pudo en la promoción de una legislación que le asegurara la expansión del sistema privado-católico de enseñanza ${ }^{18}$. El primer paso fue la asunción como ministro de educación del católico Atilio Dell'Oro Maini. Su acción más conocida fue la redacción del Decreto 6403/55, que en su artículo 28 autorizaba la creación de universidades privadas con la capacidad de emitir títulos habilitantes. La medida provocó reacciones en contra y a favor, y se organizaron marchas en todo el país esgrimiendo las consignas "laica o libre".

Los socialistas participaron activamente por la "laica" logrando suspender el artículo por un tiempo. En otros ámbitos de actuación, como la Legislatura de la provincia de Buenos Aires, se ocuparon de denunciar las visitas de sacerdotes católicos a las escuelas públicas y el contenido de la materia

15 Luciano Schilling era el presidente. Ver Juan Carlos Nigro, La lucha de los maestros (Buenos Aires: Confederación de Maestros, 1984). Sobre los socialistas y la educación en estas décadas ver Marina Becerra, "Intelectuales socialista, Estado y educación en Argentina a principios del siglo XX", Revista Confluencia, Año 3, (2007): 13-29.

16 Adriana Puiggrós, Qué pasó en la educación argentina (Buenos Aires: Galerna, 1996), 100.

17 Existen muchos documentos donde Repetto, pero sobre todo Ghioldi, califican al peronismo como "fascista", "tiranía", "dictadura" y "totalitarismo". Ver Carlos Miguel Herrera, "¿La hipótesis de Ghioldi? El socialismo y la caracterización del peronismo (1943-1956)”, en Hernán Camarero y Carlos Miguel Herrera (ed.) El Partido Socialista en Argentina (Buenos Aires: Prometeo, 2005), 343-366; Carlos Altamirano, "Estudio preliminar", en Bajo el signo de las masas (Buenos Aires: Sudamericana, 1999); Marcela García Sebastiani, "El Partido Socialista en la Argentina peronista: oposición y crisis de representación política”, Estudios Interdisciplinarios de América Latina y el Caribe, Vol. 13, 820029.

18 Fortunato Mallimaci, "Catolicismo y militarismo en argentina (1930-1983)", Revista de Ciencias Sociales, $\mathrm{N}^{\circ}$ 4, (1996): 181-218. 
sobre enseñanza moral, que equivalía a "la imposición del dogma católico"19. Unos años después se aprobaron a nivel nacional los programas para el nivel primario que habían incluido nuevamente el ítem "Noción de Dios. Deberes para con Él" 20 .

A medida que pasaba el tiempo se iban profundizando las diferencias entre los socialistas en relación a qué postura adoptar frente al gobierno dictatorial. Finalmente, en 1958 el Partido Socialista se dividió en dos fracciones, el Partido Socialista Democrático (PSD) y Partido Socialista Argentino $(\mathrm{PSA})^{21}$. Los líderes más visibles del PSD fueron Américo Ghioldi y Nicolás Repetto, quienes se autodenominaban "liberales" y "republicanos" y acusaron a los otros de ser "simpatizantes" del comunismo y el peronismo. En 1962 salió el primer número de La Vanguardia como vocero del PSD. En sus páginas se recordaban elogiosamente los aniversarios de la "Revolución Libertadora" y al general Pedro E. Aramburu.

Con la asunción del presidente Arturo Frondizi (1958-1962) fue ministro de educación otro católico, Luis R. MacKay, quien transformó en ley el artículo que habilitaba la creación de universidades privadas. Además, MacKay -junto con su subsecretario Antonio Salonia- dictó el Decreto 12719/60, en cuyo artículo primero se establecía que los institutos privados o "incorporados" de nivel medio y superior gozaban de plena autonomía. Un año antes, había creado la Dirección Nacional de la Enseñanza Privada (Decreto 7728/59), que se transformó en la Superintendencia Nacional de la Enseñanza Privada [en adelante SNEP]. El primer director fue el militante de Acción Católica Alfredo Van Gelderen. La creación de la SNEP fue para los católicos una de las medidas "más trascendentales",

19 Cit. en Silvana G. Ferreyra, Socialismo y antiperonismo: el Partido Socialista Democrático. Transformación partidaria y dinámica política en tiempos de proscripción (Provincia de Buenos Aires, 1955-1966), Tesis Doctorado Interuniversitario en Historia (Mar del Plata: Universidad Nacional de Mar del Plata, 2012) 225.

20 Laura Graciela Rodríguez, "Las ideas católicas sobre la educación en los años de 1960 y 1970 . El caso del CONSUDEC", en Hugo Cancino et. al. (comp.) Miradas desde la Historia social y la Historia intelectual. América Latina en sus culturas: de los procesos independistas a la globalización (Córdoba: Centro de Estudios Históricos Carlos Segretti, 2012), 889-904, e-book.

18821 Sobre el PSD en estos años, ver Silvana G. Ferreyra, Socialismo y antiperonismo. En el PSA quedaron, entre otros, Alfredo Palacios y Alicia Moreau de Justo. Un análisis detallado de la división y el derrotero posterior del PSA está en María Cristina Tortti, El "viejo" Partido Socialista y los orígenes de la "nueva" izquierda (Buenos Aires: Prometeo, 2009). 
"más revolucionaria" y "más importante" de la historia de la educación privada que coronaba "el boom de expansión de la enseñanza privada" que venía desarrollándose "desde 1950 y sobre todo desde 1956"22.

En 1959 un grupo de maestros y profesores normalistas fundó la Confederación Argentina de Maestros y Profesores (CAMYP) sobre la base de la Liga de Profesores y la Confederación de Maestros. Los referentes más conocidos de la Confederación eran Ghioldi, José S. Campobassi y Alfredo P. Bravo. Cabe señalar que los dos primeros eran del PSD, pero Bravo había sido expulsado del Partido en 1956, aunque seguía autodefiniéndose como socialista ${ }^{23}$. Habían apoyado activamente la campaña para sancionar un nuevo Estatuto del Docente -en reemplazo del elaborado por el peronismo- y que finalmente se convirtió en la Ley 14473 en $1958^{24}$. En síntesis, la CAMYP decía haberse creado para defender la aplicación del Estatuto y asegurar la vigencia plena de la Ley 1420.

Por su parte, la Liga Argentina de Cultura Laica (LACL) tenía por presidente en esos años al maestro normal y profesor de filosofía Atilio Torrasa, ligado al PSD. Antiperonista, en los años de 1940 se negó a reeditar su Tratado de lógica "para no desarrollar los temas políticos y religiosos del programa de Filosofía impuesto por el peronismo"25. Conocía a Ghioldi de los encuentros de normalistas y le había prologado uno de sus libros sobre Mitre. Allí Ghioldi advertía que "ante una nueva y violenta agresión llevada contra la escuela popular de Sarmiento y la civilizadora Ley 1420, restituida oportunamente por la Revolución Libertadora, la exhumación de los escritos del liberalismo argentino... constituye tanto un acto de justicia como un valiosísimo aporte al esclarecimiento del proceso de nuestras ideas-fuerza". En el libro, Torrassa decía que la Ley 1420 "propulsó

22 Consudec, $\mathrm{N}^{\circ}$ 529, agosto 1985.

23 Según Bravo, él y otros militantes fueron expulsados del PS en 1956 por promover el debate interno sobre el peronismo. Entrevista a Alfredo P. Bravo en Silvia Andrea Vázquez y Juan Balduzzi, De Apóstoles a trabajadores. Luchas por la unidad sindical docente 1957-1973 (Buenos Aires: CTERA, 2000), 24.

24 http://www.camyp.com.ar/articulo/Historia_44 [visitado el 4 de mayo de 2015]

25 Atilio Torrassa, Mitre, paladín del laicismo. La enseñanza neutral o laica y la enseñanza libre. (Buenos aires: Ediciones de Sarmiento, 1957), 3. Torrassa había escrito también: Introducción a las disciplinas de la cultura. Resúmenes de las clases dadas en la Escuela de Bibliotecarios, 1954 y 1955; Legislación Escolar Argentina Tomo 1: enseñanza Primaria, (Buenos Aires: Ed. Sarmiento, 1956); La educación del pueblo notas publicadas en el diario "Crítica" escritas entre 1930 y 1946; Sección educación en la revista Qué, durante la primera época hasta el cierre de la revista por el gobierno peronista. 
vigorosamente la grandeza del país, de tal suerte, que de uno de los más atrasados del punto de vista educativo se colocó, a los cincuenta años de su vigencia, entre los más progresistas" ${ }^{26}$.

Otro referente de la Liga fue el mencionado Campobassi, maestro, egresado también de la Escuela Mariano Acosta; dio clases durante varios años en un establecimiento ubicado en el barrio de La Boca junto con su hermano Carlos Alberto. Llegó a conocer a Juan B. Justo; era discípulo de Nicolás Repetto y trabajó en La Vanguardia ${ }^{27}$. En 1935 con motivo del cincuentenario de la Ley 1420, el Consejo Nacional de Educación lo premió y editó su libro La educación primaria desde 1810 hasta la sanción de la Ley Nacional 1420. En 1938 la misma institución lo volvió a distinguir por su monografía "Sarmiento y la educación pública" con motivo del cincuentenario de la muerte del prócer. En 1956 dio a conocer el libro llamado Ley 1420 (Buenos Aires: Gure, 1956) ${ }^{28}$.

En estos años de la segunda posguerra Ghioldi se involucró -junto con otros socialistas como Campobassi- en el movimiento del Congreso por la Libertad de la Cultura, experiencia de la que participaron importantes figuras de la educación como el pedagogo norteamericano John Dewey ${ }^{29}$. Dicho movimiento se creó en el marco de la "guerra por las ideas" o "guerra fría cultural" que llevó a buena parte de los intelectuales del mundo occidental y en especial a los socialistas argentinos a manifestarse contrarios a la "censura y el totalitarismo" tanto de izquierda o derecha (especialmente el comunismo soviético, el franquismo español y los nacionalismos latinoamericanos), y a favor de la defensa de la "democracia liberal" 30 .

26 Atilio Torrasa, Mitre, paladín del laicismo, 16.

27 José S. Campobassi, Nicolás Repetto (Buenos Aires: Editora La Vanguardia, 1980). Los datos de la biografía están en el capítulo "Larga amistad y fecunda maestría" (1980), 87-96.

28 Escribió posteriormente dos trabajos que también fueron distinguidos: "Orígenes, fundación e historia de la Escuela Normal Mixta de Concepción del Uruguay" (1949) y "Urquiza y el Colegio Histórico del Uruguay”, entre otros. También desarrolló ciclos de conferencias radiofónicas sobre temas educativos e históricos entre los años de 1920 y 1930.

29 Karina Jannello, "Las políticas culturales del socialismo argentino bajo la Guerra Fría. Las redes editoriales socialistas y el Congreso por la Libertad de la Cultura”, Papeles de Trabajo, año 7, $\mathrm{N}^{\circ} 12$, (2013): 212-247.

30 Sobre el pensamiento de Ghioldi durante el período anterior, ver Ricardo Martínez Mazzola, "Justo, Korn, Ghioldi. El Partido Socialista y la tradición liberal", Papeles de trabajo, N 8, (2011): 35-52. En relación a las vinculaciones con Estados Unidos, ver Karina Jannello, "Las políticas culturales". 
Si Ghioldi consideraba que Sarmiento estaba siendo atacado en esos momentos por los grupos de católicos "totalitarios", el eje de la actuación pública e intelectual de los socialistas del PSD fue escribir y hablar en su defensa, a riesgo de plantear cuestiones similares en todos los textos. En dos años Campobassi publicó cuatro libros: Sarmiento y la Ley 1420 (Santa Fe: Universidad Nacional del Litoral, 1960); Sarmiento: sus ideas sobre religión, educación y laicismo: respuesta a un libro antisarmientista (Buenos Aires: Liga Argentina de Cultura Laica, 1961); Laicismo y catolicismo en la educación pública argentina (Buenos Aires: Gure, 1961); y Sarmiento y Mitre: hombres de Mayo y Caseros (Buenos Aires: Losada, 1962).

Luego del golpe de Estado que derrocó a Frondizi en 1962, asumió la presidencia Arturo Illia (1963-1966) y los referentes de la CAMYP le entregaron un memorándum donde desarrollaban cuáles eran los pasos que tenían que seguir los nuevos gobernantes en materia educativa ${ }^{31}$. En el documento sostenían que el Poder Ejecutivo Nacional debía hacer todo lo posible para incrementar gradual y proporcionalmente el presupuesto destinado a la educación pública; combatir el analfabetismo creando diez mil escuelas en el término de seis años y jardines de infantes progresivamente obligatorios en todo el país; aumentar las escuelas de doble escolaridad con comedores escolares gratuitos y extender la obligatoriedad de la enseñanza de siete a diez años. Pedían que se dejara de subsidiar a las escuelas privadas allí donde existiesen institutos oficiales de educación, y que el Estado no elevase los subsidios al sector. Solicitaban revisar toda la legislación educativa que atentaba contra el interés del Estado y planteaban que dejaran de autorizarse escuelas normales privadas y se cerraran las existentes, ya que "maestros y profesores, como los oficiales de las fuerzas armadas, solo debían ser formados en escuelas del Estado". Concluían que la inspección de las escuelas oficiales y privadas debía ser única, en tanto el sistema actual era proclive "a la irregularidad organizada lindante con la inmoralidad”, entendiendo que la SNEP debía dejar de funcionar.

Ese mismo año el sacerdote Septimio Walsh fundó el periódico Consudec

31 Todas las referencias son del "Memorandum de CAMYP", Archivo Universidad Popular Alejandro Korn (UPAK). El memorándum fue publicado también en Consudec, № 2, 5 septiembre 1963, 8. 
(1963) del Consejo Superior de Educación Católica (CONSUDEC). Tenía entre 24 y 28 páginas; recibía publicidad de las distintas escuelas católicas, de empresas del rubro educativo y de organismos oficiales ${ }^{32}$. Desde los inicios, religiosos y laicos se ocuparon de contestar lo que consideraban "agravios" que proferían tanto la CAMYP como LACL.

El presidente Illia nombró a Carlos Alconada Aramburú como ministro y designó presidente de la SNEP a Marcos Pedro Ronchino, miembro del Opus Dei. Desde allí logró que se aprobaran dos decretos, el 15/64 y el $371 / 64$. Por el primero se normalizó todo lo referente a la distribución y fiscalización del aporte estatal a los institutos de enseñanza no oficiales de la jurisdicción nacional. Por el segundo, se sistematizó lo relacionado con el reconocimiento de los estudios cursados en los niveles medio y terciario de esos mismos institutos. Los católicos habían recibido los "excelentes" decretos con "alegría" y "satisfacción"33.

A fines de 1963 Torrassa dio a conocer el comunicado de la LACL llamado "Se ataca a Sarmiento en las escuelas privadas" dirigido al ministro Alconada Aramburú y del cual se hizo eco el Consudec ${ }^{34}$. Torrassa repudiaba los ataques a los monumentos de Domingo F. Sarmiento que habían sido perpetrados por militantes de la organización nacionalista y católica de derecha "Tacuara" en varias ciudades del país ${ }^{35}$. Sin nombrar a Tacuara, Torrassa denunciaba que sus militantes habían repartido folletos entre los alumnos de las escuelas privadas, a las que acusaba de estar "regidas por congregaciones extranjeras" que tenían escasa "identificación nacional y democrática” y que vanagloriaban a "tiranos y caudillos, en especial a Ro-

32 Acerca del periódico Consudec, ver Laura Graciela Rodríguez, "Las ideas católicas sobre la educación en los años de 1960 y 1970".

33 Consudec, $\mathrm{N}^{\circ}$ 491, enero 1984.

34 Todas las referencias son del comunicado publicado por la Liga Argentina de Cultura Laica (LACL) "Se ataca a Sarmiento en las escuelas privadas", Archivo UPAK. También fue dado a conocer en Consudec, No 3, 5 diciembre 1963, 14. Por la Liga, Torrassa había publicado la introducción al estudio sobre Victor Hugo y la libertad de enseñanza con la reproducción integra del famoso discurso que pronunciara en la Asamblea Legislativa de Francia, en 1850, en 1962.

35 Sobre Tacuara y este episodio ver María Valeria Galván, El nacionalismo de derecha en la Argentina posperonista. Un cuadro de sus cambios y continuidades en la larga década del sesenta a partir de la lectura del semanario Azuly Blanco (1959-1969) (Rosario: Prohistoria, 2012). 
sas, Facundo y el Chacho"36. Otro de los problemas, seguía Torrassa, era que en esos establecimientos se usaban textos que decían que Sarmiento era blasfemo, sacrílego, hereje, masón, falaz, impío y grosero, entre otros adjetivos descalificadores hacia su persona. Con base en estas pruebas, la Liga pedía al Ministerio: 1) examinar los libros de texto usados en las escuelas privadas; 2) determinar el autor de los "libelos" contra Sarmiento y la relación de los mismos con los colegios privados; 3) retirar el subsidio y clausurar todos los colegios que usaran textos o difundiesen doctrinas contrarias a "nuestro espíritu democrático"; 4) realizar "una prolija inspección por medio de los inspectores, directores y profesores de los colegios oficiales acerca de los programas y la forma de enseñar historia, educación democrática, filosofía, pedagogía, historia de la educación y de la cultura"; 5) revisar todos los decretos "ilegales" con que se había concedido, violando las Leyes 934 y 1420, la total autonomía a la enseñanza privada "al punto de constituir un ente autónomo dentro del Estado" [en referencia a la SNEP] ${ }^{37}$.

En el medio del conflicto, la LACL publicaba la Introducción escrita por Torrassa a un libro llamado: Sarmiento y la libertad de enseñanza: un artículo enjundioso no incluido en las obras completas del gran maestro (Buenos Aires: Liga Argentina de Cultura Laica, 1963 $)^{38}$. Al poco tiempo Torrassa envió una segunda nota al Ministerio en la cual volvía a denunciar el contenido de los textos escolares, identificando a los autores de los libros de texto mencionados: Francisco Arriola, Juan Díaz y Germán J. Bidart Campos, quienes "denigraban" a la Revolución Francesa "inspiradora de la emancipación americana y la tradición de Mayo", ocultando y deformando las ideas de "nuestros próceres". Torrassa pedía a las autoridades que prohibieran la circulación de los libros llenos de "odio delirante" que se imprimían en editoriales católicas, se vendían en librerías católicas y se difundían en escuelas católicas "encendiendo reacciones vandálicas en niños y jóvenes desprevenidos". Finalizaba solicitando nuevamente que se encontrara al autor del "libelo", se retirase el subsidio y se clausurasen las escuelas que lo usaran.

36 Torrassa, Atilio, "Se ataca a Sarmiento en las escuelas privadas", LACL, Archivo UPAK.

37 Torrasa, Atilio, "Se ataca a Sarmiento en las escuelas privadas", LACL, Archivo UPAK.

38 En 1965 Torrassa publicaría Filosofía de la educación: grandes figuras de la pedagogía: legislación escolar (Buenos Aires: Edicon, 1965). 
Torrasa no lo hacía explícito, pero se sabía que "En torno a Sarmiento" había sido escrito por el profesor católico Blas Barisani, integrante del Opus Dei, director de la revista Cuadernos del Sur y autor de los libros sobre "Educación Democrática". Unos meses después Torrassa dio a conocer el contenido de estos textos de la editorial Claretiana. Decía que en ellos se predicaba a favor del "corporativismo falangista" y el "lusitano", que pensaban que todo lo liberal y democrático era una "horrenda herejía". Se insultaba a los "verdaderos próceres" como Moreno, Rivadavia y Alberdi, se ensalzaba a Rosas promoviendo "los nacionalismos totalitarios", y se decía que todo lo referido a la Constitución era "aberrante, incongruente e impopular" 39 . Estas apreciaciones se acompañaron con una denuncia formal que hizo la LACL ante el Ministerio de Educación y Justicia titulada "Escuela sectaria y textos de educación democrática: documentada denuncia al Ministerio" (1964).

A través del periódico Consudec los católicos se ocuparon de contestar las declaraciones de Torrassa. En una de las notas negaban que el contenido de los manuales tuviese algo "reprochable" y afirmaban que el planteo de LACL, que pretendía que el Estado controlase la enseñanza privada, suprimiese los subsidios al sector y cerrase las escuelas normales privadas, parecía un "chiste" de "humor negro"

En febrero de 1964 los dirigentes de CAMYP presentaron a la Comisión de Educación de la Cámara de Diputados un memorándum que proponía la supresión legal de los subsidios a la enseñanza privada, aunque no prosperó. Desde el Consudec contestaron que la propuesta y sus argumentos eran "falsos, absurdos y de pesadilla" 41 . Poco después los católicos le respondían a la LACL sobre el mismo tema ${ }^{42}$. Si se suprimía el subsidio estatal, decían, se generaba "un problema insoluble de salarios docentes pues los padres no podrían soportar las alzas inconmensurables de aranceles de enseñanza que ello originaría, con lo que en la práctica desaparecería la enseñanza privada ¿eso es lo que pretende la Liga?”.

39 La Vanguardia (LV), 18 marzo 1964, 3 y 4. Barisani escribió los libros de texto de la materia "Formación Moral y Cívica" durante la última dictadura.

40 Consudec, $\mathrm{N}^{\circ} 28,20$ septiembre 1964, 1.

41 Consudec, $\mathrm{N}^{\circ} 34,20$ diciembre 1964, 1.

42 Consudec, N 56, noviembre 1965, 1. 
En relación con esto, a fines de 1964 los católicos se quejaban por el "increíble atraso" del pago del aporte estatal ${ }^{43}$. A principios de 1966 continuaban con el tema y hablaban del "vía crucis de los docentes privados" y decían que los maestros y profesores que ejercían en institutos gratuitos estaban padeciendo una "situación insoportable" que ya tenía "cinco meses de demora", sin contar otros abonos que no se hicieron en todo el año 1965, como por ejemplo el aguinaldo o las vacaciones ${ }^{44}$. Según la nota, había profesores "desnutridos", que no tenían dinero para pagar el colectivo, lustrarse los zapatos o comprar dentífrico. En esos momentos, aseguraban, "no hay vergüenza mayor en el país".

\section{Los AÑos DE LA DICTADURA (1966-1973) Y EL TERCER GOBIERNO PE- RONISTA (1973-1976)}

A mediados de 1966 se produjo el quinto golpe de Estado ("Revolución Argentina”) al mando del general Juan Carlos Onganía. La CAMYP, presidida en esos años por Alfredo P. Bravo y Emilio De Cecco -autor de manuales de matemática para el nivel primario e integrante del PSD-, le hicieron llegar a las nuevas autoridades un documento donde solicitaban la vigencia de la Ley 1420 y del Estatuto ${ }^{45}$. Además, reiteraban la necesidad de incrementar los recursos para la enseñanza pública; que los subsidios a las privadas se limitaran a escuelas que cumpliesen una "verdadera función social sin discriminaciones económicas ni religiosas" dentro del "espíritu democrático y laico"; que la estabilidad del docente de enseñanza privada quedase asegurada y los propietarios pagaran el sueldo íntegro a los docentes cuando el subsidio se atrasaba; que la formación de maestros y profesores quedara en manos exclusivamente del Estado y la enseñanza privada estuviese controlada por los mismos organismos de inspección de la enseñanza oficial. Avanzado el régimen, los gremialistas denunciaron que existía una "virtual derogación” del Estatuto, en tanto no se había llamado a concurso para la designación de los cargos docentes ${ }^{46}$.

43 Consudec, $\mathrm{N}^{\mathrm{O}} 34,20$ diciembre 1964.

46 LV, 11 junio 1969, p. 5. 
Dos años después, el encargado de la cartera educativa, el católico José Mariano Astigueta, anunció la intención de derogar la Ley 1420 y presentó el texto del anteproyecto de Ley de Educación que había sido elaborado por personalidades ligadas a la educación privada y católica. El manuscrito recibió las críticas generalizadas de amplios sectores y el anteproyecto debió ser abandonado. La LACL dio a conocer un manuscrito sin firma llamado: "El gran salto atrás: anteproyecto de Ley Federal de Educación" (Buenos Aires: Liga Argentina de Cultura Laica, 1968) y la CAMYP y otros gremios también se manifestaron en contra.

Simultáneamente, las autoridades anunciaron el inicio de una "reforma educativa". Previsiblemente, las dos propuestas fueron apoyadas por el Consudec $^{47}$. Del lado de quienes se opusieron estuvo Alfredo Bravo. Sostuvo que había que dar un "no rotundo a la reforma totalitaria, negativa e inconsulta" que "desvirtuaba a la escuela sarmientina" y pretendía "reducir el nivel cultural de los menos pudientes" en tanto era un "intento extranjerizante" que bebía "de la fuente española y franquista", régimen totalitario que repugnaba "a nuestra condición de hombres libres, pensantes y democráticos" ${ }^{48}$. Escribió además un artículo llamado "La reedición de la Escuela Intermedia" donde explicaba, entre otras cuestiones, que el problema principal de la reforma era que pretendía acortar los años de la obligatoriedad de siete a cinco ${ }^{49}$. Luego de varios años de luchas docentes, la reforma fue suspendida en 1971.

Para esa época los dirigentes de la CAMYP denunciaron que funcionarios del Ministerio de nación y de la provincia de Buenos Aires habían comprado libros de textos impresos en España para los programas de la reforma educativa, cometiendo "gravísimas irregularidades" 50 . Se acusaba a los funcionarios de la SNEP, Marcos Ronchino y Van Gelderen, de ha-

47 Sobre el anteproyecto de Ley, la reforma y la posición del CONSUDEC, ver Laura Graciela Rodríguez, "Los católicos desarrollistas en Argentina. Educación y planeamiento en los años de 1960", Diálogos, Vol. 17, № 1, (2013): 155-184 [en línea]

$19648 \quad \mathrm{LV}, 10$ noviembre 1970, p. 1.

49 Alfredo P. Bravo, "La reedición de la Escuela Intermedia", en Aníbal Villaverde (coord.) La escuela intermedia en debate (Buenos Aires: Humanitas, 1971), 219-230.

50 LV, 25 noviembre 1970, p. 1. 
bérselos encargado a una imprenta del Opus Dei (organización a la que pertenecía el primero). Mostraban además que los manuales tenían errores en la confección de los mapas del país, equivocando el nombre de las provincias. Los gremialistas planteaban que la reforma era un "gran negocio" para instituciones privadas como la Escuela Argentina Modelo ligada a Van Gelderen, donde se realizaban los cursos de actualización para los docentes, quienes tenían que pagar una "elevada matrícula". En resumen, la CAMYP reclamaba a las autoridades del Ejecutivo "el inmediato examen por la posible vinculación de asesores del área educativa con editoriales e institutos privados para beneficiarse con la reforma educativa".

Ese año Torrassa publicó un artículo llamado "La secularización del Estado en la Argentina", donde hacía un diagnóstico negativo sobre lo que estaba ocurriendo en el país y se dedicaba a denunciar el avance de la legislación que favorecía a la educación privada, las políticas presupuestarias que estaban desfinanciando al sector público, el cierre de escuelas públicas y la mala calidad de las universidades privadas ${ }^{51}$. En referencia a esto último, la Liga realizó varias peticiones a las autoridades para que controlaran las casas de estudio privadas que se estaban abriendo y la enseñanza que se impartía, para evitar que se atentase "contra los principios liberales y republicanos de la nacionalidad consubstanciados con los ideales de Mayo, Caseros y la Constitución Nacional" 52 .

En 1969 la LACL envió a un representante, Emilio J. Corbière, del PSD, al Coloquio Latinoamericano de Educación que se realizó en Caracas (Venezuela) en septiembre. El delegado argentino presidió la comisión que trató el tema de la situación educativa en América Latina y la realidad socioeconómica. Durante el plenario se aprobaron resoluciones sobre el aspecto doctrinario del laicismo que fueron transcritas en La Vanguardia ${ }^{53}$.

Hacia 1970 Torrassa se encontraba trabajando en la provincia de Tucumán y la LACL renovó autoridades, eligiendo como presidente a Walter V.

51 Atilio E. Torrassa, "La secularización del Estado en la Argentina", en Pedro Lamarque, Transformación de las instituciones públicas y laicidad en Europa occidental” (Rosario: Ediciones Trabajo, 1968), 5-34.

52 LV, 6 diciembre 1967, 3.

53 LV, 20 septiembre 1969, 2. 
Constanza, del PSD ${ }^{54}$. Este nombramiento coincidió con la llegada de un nuevo presidente de facto, por lo que Constanza le acercó un petitorio que repetía lo solicitado en ocasiones anteriores ${ }^{55}$. A través de La Vanguardia, las autoridades saludaban la reciente creación del Movimiento de Afirmación y Progreso de la Educación (MAPE), que enarbolaba las mismas banderas.

En 1971 Torrassa elaboró para el sindicato de Tucumán un informe sobre La reforma educativa: análisis crítico de todos los documentos oficiales que salió editado por la Agremiación Tucumana de Educadores Provinciales (Tucumán: ATEP, 1971) ${ }^{56}$. Torrassa falleció al poco tiempo y un importante dirigente local, Isauro Arancibia, le escribió un sentido homenaje $\mathrm{e}^{57}$.

Las numerosas acciones organizadas alrededor de la reforma fueron reconfigurando el espacio sindical docente. Desde 1970 se constituyeron diversas agrupaciones locales, zonales y regionales, asambleas a nivel general, constitución de federaciones o confederaciones, tanto del sector de los docentes privados como públicos. Se fueron fundando, entre otros, el Acuerdo de Nucleamientos Docentes (AND), la Central Unificadora de Trabajadores de la Educación (CUTE) y en 1973 se creó la Confederación de Trabajadores de la Educación de la República Argentina (CTERA). Los primeros secretarios de CTERA fueron de la CAMYP, Carlos Alberto Rocchi y Alfredo P. Bravo. En el acta de fundación se definió que el maestro pertenecía "a la clase trabajadora" descartando las definiciones "profesionalistas" que esgrimían otras entidades ${ }^{58}$. Frente a un nuevo gobierno peronista (1973-1976) Alfredo Bravo simpatizó en los inicios con su ala izquierda y se convirtió en el dirigente más visible de la CTERA. A me-

54 Los resultados de la asamblea general realizada por la LACL quedaron así: presidente Walter Constanza; vice Antonio Cartaña; secretario José Antonelli; pro secretario Marcelo Castreana; tesorero Roberto P. Saint Genez; vocales titulares Emilio J. Corbière, Valentín Gutiérrez, Martín Egozcue, Rolando M. Rivière, Carlos A. Solimano y Rafael S. Hassan; vocales suplentes Benjamín Zubiaur, Osvaldo Quiroga, Alfredo Khon Loncariga, Enrique R. Rezcke, Felipe Waolchejosky y Floreal O. Spagnoli.

19855 LV, 24 junio 1970, 3.

56 LV, 3 octubre 1971, 5.

57 Isauro F. Arancibia, "Homenaje a Atilio Torrasa", Propósitos, No 427, 13 enero 1972.

58 Silvia Andrea Vázquez y Juan Balduzzi, De Apóstoles a trabajadores. 
diados de 1974 se ocupó de denunciar los avances de la derecha peronista en las universidades a partir de la gestión del ministro de educación Oscar Ivanissevich. Al año siguiente ayudó a organizar la Asamblea Permanente por los Derechos Humanos (APDH) ${ }^{59}$.

Paralelamente, en el Consudec se quejaban del "incumplimiento crónico" de los aportes que debía hacer el Estado a los establecimientos privados y el “congelamiento" de los montos desde 1969. En una solicitud pedían que el gobierno nacional actualizara los pagos; mantuviera el $100 \%$ del aporte para los colegios gratuitos de Capital Federal; que para los colegios del interior el aporte estatal abarcase la totalidad de los sueldos del personal docente, administrativo y de maestranza, el mantenimiento de los edificios escolares, como así también para el material didáctico necesario, y se posibilitara la creación de nuevas escuelas, especialmente técnicas, en "zonas pobres y marginadas" ${ }^{60}$.

\section{La Última dictadura (1976-1983): LA "SUbVERSión APLASTADA"}

Durante la última dictadura iniciada el 24 de marzo de 1976, un importante conjunto de docentes afiliados a CTERA fue encarcelado, asesinado y/o desaparecido, como el tucumano Arancibia ${ }^{61}$. El caso más resonante fue la detención de su secretario general, Alfredo Bravo, en septiembre de $1977^{62}$. Lo que quedaba de la Junta Ejecutiva del gremio -Armando Pérez y Benito Brusser- se reunió con distintos dirigentes y realizaron una denuncia internacional. Se generó una fuerte presión y la Junta Militar debió liberarlo en junio de 1978. Fue puesto en su domicilio bajo el régimen de "libertad vigilada" y se constató que su cuerpo mostraba signos de haber sido torturado. Igual que en otros casos, la actividad gremial se redujo al mínimo y los escasos integrantes de la Junta Nacional en funciones se vieron abocados a concretar gestiones de Habeas Corpus y a llevar asistencia a

59 CTERA, Universidad: la 'Misión' del caos y la destrucción. Documento preparado y diagramado por las secretarías de la rama universitaria y de relaciones gremiales de la CTERA y su edición fue costeada con el aporte de los docentes (Buenos aires: CTERA, 1975).

60 Laura Graciela Rodríguez, "Las ideas católicas sobre la educación en los años de 1960 y $1970 "$.

61 Silvia Andrea Vázquez y Juan Balduzzi, De Apóstoles a trabajadores.

62 El Dia, 21 septiembre 1977, 2. 
docentes detenidos o que debían exiliarse. Pese a las limitaciones, la CTERA continuó criticando públicamente las medidas ligadas a las reformas del Estatuto y a la política emprendida en el ámbito de la Capital Federal ${ }^{63}$.

Mientras se sucedían estos acontecimientos, la CAMYP decidió expulsar a Bravo de sus filas, los dirigentes del PSD asumieron como funcionarios del gobierno dictatorial y avalaron la represión estatal. Por ejemplo, Ghioldi fue embajador de Portugal entre 1976 y 1979. En un editorial aparecido en La Vanguardia felicitaban a los militares porque la "subversión" había sido "aplastada" y afirmaban: "no lo decimos solo en base a lo que afirma el gobierno, sino también porque reconocemos públicamente el clima de tranquilidad y seguridad que se advierte en todos los ámbitos de la República" ${ }^{64}$. En otra ocasión, comentaron elogiosamente el documento Subversión en el ámbito educativo. Conozcamos a nuestro enemigo dado a conocer en 1977, que se había elaborado para facilitar la "comprensión del fenómeno subversivo que vivía la Argentina de esos días" "65. Los socialistas explicaban que "aparte del valor informativo y didáctico de la publicación, corresponde destacar la exactitud con que se fija, en ella, el verdadero significado e importancia de la función educativa, al reconocerse que la grandeza y la proyección histórica de las naciones dependen fundamentalmente de la educación que se brinde a sus pueblos"66.

Así también, se manifestaron de acuerdo con la grave denuncia que habían hecho los padres de un colegio católico de la Capital Federal acerca de "la acción disolvente" que estaba llevando a cabo un equipo de "catequistas y profesores" que utilizaba la revista El Mensajero de San Antonio, conocida, decían, por su "prédica extremista". La publicación era editada por la orden de los Frailes Franciscanos Conventuales de Padua (Italia) y los socialistas afirmaban que a ella pertenecían "los curas terroristas que

63 Sobre lo ocurrido en el área educativa en esos años, ver Laura Graciela Rodríguez, Católicos, nacionalistas y politicas educativas durante la última dictadura (1976-1983) (Rosario: Prohistoria, 2011).

64 LV, 5 julio 1979, 1.

20065 Ministerio de Cultura y Educación, Subversión en el ámbito educativo. Conozcamos a nuestro enemigo, (Buenos Aires: MCyE, 1977). Sobre el contenido completo del documento, ver Laura Graciela Rodríguez, Católicos, nacionalistas.

66 LV, 8 octubre 1978, 4. 
colaboraban con monseñor Angelelli" ${ }^{67}$. El mencionado religioso había sido asesinado por las fuerzas represivas en 1976. Es decir, a pesar de su incansable prédica laicista, estos socialistas no dudaron en ponerse del lado de los católicos más reaccionarios y acusar al clero progresista. Al año siguiente el Comité Ejecutivo Nacional del partido expresó que le parecía inadecuada la llegada de la Comisión Interamericana de Derechos Humanos (CIDH) al país, ya que "acumular denuncias" [sobre las violaciones a los derechos humanos] no arrojará ninguna "luz sobre la gravedad de lo ocurrido en el país"68.

Al mismo tiempo, los gremialistas docentes ligados al PSD como Arístides A. Incarnato, Héctor A. Robles y Augusto Guibourg de CAMYP, la Confederación de Maestros y del Centro de Profesores Diplomados de Enseñanza Secundaria, criticaron todas y cada una de las medidas referidas al aporte a la educación privada y la necesidad de que el Estado supervisase al sector, al sesgo católico de ciertos programas y la transferencia de las escuelas primarias nacionales a las provincias, entre otras cuestiones. Lo mismo hizo el presidente de la LACL, Adolfo J. E. Morano ${ }^{69}$. En particular, los socialistas hicieron foco en el nuevo intento de derogación de la Ley 1420. El ministro Juan R. Llerena Amadeo había presentado en 1979 un anteproyecto de Ley de Educación que había sido elaborado por exfuncionarios vinculados a la reforma educativa de la dictadura anterior $(1968)^{70}$. Morano fue particularmente crítico con este mandatario y sus colaboradores, que eran los más vinculados a la jerarquía de la Iglesia Católica.

De su lado, los católicos seguían respondiendo a sus antiguos enemigos. Por ejemplo, sostenían que resultaba "absolutamente imposible una enseñanza neutra, organizada al margen de cualquier constitutivo cultural religioso" ${ }^{\prime}$. Y volvían al argumento que las estadísticas eran "manipuladas por el sectarismo" y que si el Estado tuviese que asumir "toda la enseñan-

$67 \quad$ LV, 2 de marzo de 1978, 3.

68 LV, 20 septiembre 1979, 1.

69 LV, 22 diciembre 1970, 2. Adolfo J. E. Morano había publicado un folleto titulado Educación común y enseñanza privada (Buenos Aires: Liga Argentina de Cultura Laica, 1971).

70 Laura Graciela Rodríguez, Católicos, nacionalistas.

71 Consudec, $\mathrm{N}^{\circ} 348,5$ enero 1978. 
za" esto no significaría un ahorro para el país, dado lo costosa que era la enseñanza oficial, por ende, sostenían que la enseñanza privada le salía más barata al Estado.

En esos años la LACL se ocupó también del problema limítrofe, cuestión que fue muy relevante para el gobierno dictatorial, cuyos militares alimentaron un nacionalismo xenófobo contra Chile que casi termina en una guerra con ese país. En 1977 la LACL publicó de Campobassi Sarmiento y la defensa de la Patagonia (Buenos Aires: Liga Argentina de Cultura Laica, 1977); en 1980 el mismo autor escribió un libro en homenaje a Repetto y otro sobre Mitre y su época (Buenos Aires: Eudeba, 1980) ${ }^{72}$. En 1981 Campobassi recibió un premio de literatura y publicó Argentina en el Atlántico. Chile en el Pacifico (Buenos Aires: Librería Platero, 1981) ${ }^{73}$.

Hacia el final de la dictadura, la CTERA y otros gremios organizaron una serie de paros docentes reclamando distintas cuestiones como el fin de la dictadura y la apertura democrática. Ante las medidas de fuerza, la CAMYP decidió "dejar en libertad de acción a sus entidades de base"74. Según su interpretación, los paros dispuestos estaban procurando formar "un sindicato único y totalitario mediante la fusión de la Unión de Docentes Argentinos (UDA), y CTERA". El paro, continuaba, estaba destinado "a desestabilizar al próximo gobierno constitucional" si este resultaba "desafecto al pensamiento político de esos sectores" [refiriéndose al peronismo].

72 José S. Campobassi, Nicolás Repetto. En 1977 Campobassi había sido incorporado como colaborador del Suplemento Literario de La Nación -periódico afín a la dictadura- y allí publicó una serie de trabajos sobre el problema limítrofe argentino-chileno, a propósito del laudo arbitral británico de mayo de ese año, al que consideraba plagado de errores. Según contaba en otro libro, su interés se remontaba al año 1933, cuando el diputado nacional Repetto le había aconsejado que comenzase a estudiar los problemas relacionados con las fronteras argentinas. En 1949, a pedido de Saavedra Lamas escribió un trabajo sobre "Los pactos de Mayo" que analizaba los acuerdos argentino-chilenos de 1902. En 1966 había publicado Sarmiento frente a una acusación de traición a la Patria: la cuestión de los limites con Chile y el problema de la Patagonia (Buenos Aires: Liga Argentina de Cultura Laica, 1966). Este trabajo había sido premiado por el Centro Naval con motivo del sesquicentenario de la Declaración de la Independencia Nacional y contestaba las posturas de los revisionistas en relación a la "traición" de Sarmiento. Luego dio a conocer un segundo manuscrito, Sarmiento y su época que fue prologado por Repetto (Buenos Aires: Losada, 1975).

73 En 1985 participó de una compilación encabezada por Héctor Félix Bravo, A cien años de la ley 1420 (Buenos Aires: CEAL, 1985).

74 LV, 7 julio 1983, 3. 


\section{REFLEXIONES FINALES}

En este artículo nos preguntamos, por un lado, cuál fue el modelo de educación laica que promovían la CAMYP y la LACL, quiénes eran sus líderes y en qué se distinguía cada organización; y por el otro, qué papel asumieron estos grupos en el proceso de laicización que fue de 1955 a 1983. Frente a lo que había sucedido en el período inmediatamente anterior (1930-1955) cuando primero en las provincias, y luego en todo el país se implementó la enseñanza católica obligatoria en las escuelas públicas, un conjunto de maestros varones egresado de las Escuelas Normales y que adhería a los principios del Partido Socialista, creyó que una vez alejado el peronismo del gobierno, todo se encauzaría para consolidar el modelo laicista de educación siguiendo los lineamientos de la Ley 1420. A poco de comenzar esta nueva etapa, los socialistas - mayormente del PSD-comprendieron que debían reforzar sus organizaciones afines -la CAMYP y la LACLy actuar como grupo de presión al poder político: cada vez que asumía un nuevo presidente, solicitaban audiencia y les hacían llegar un petitorio que resumía los principales puntos del programa laicista que consistían en nombrar a funcionarios en el área educativa consubstanciados con la causa laica; dejar de subsidiar al sector privado; no resignar la supervisión del sistema, y consolidar la versión liberal de la historia cuya figura central era Sarmiento, entre otras cuestiones. A medida que avanzaban los sucesivos gobiernos, iba quedando claro que el modelo laicista no sería aplicado en todos sus puntos y más bien lo contrario: la Iglesia y sus funcionarios lograron la ley de creación de universidades privadas; se fundó un área de supervisión propia, la SNEP, que contó con directores de Acción Católica y del Opus Dei, y se reforzó la autonomía de los colegios privados al punto que usaban textos escolares que eran afines a una mirada revisionista, católica e hispanista de la historia, diametralmente opuesta a la que proponían los laicistas.

En relación a las diferencias que existían entre la CAMYP y la LACL, mostramos que la primera actuaba como un gremio docente, era más masiva y heterogénea en su composición y uno de sus dirigentes, Alfredo Bravo, se identificaba como socialista pero había sido desafiliado del partido. En cambio, la LACL era parte del PSD, tenía menos integrantes y en su mayo- 
ría eran intelectuales que participaban en redes y eventos internacionales y publicaban libros en el marco de la guerra fría cultural y el "combate" a los "totalitarismos". Las obras escritas en esos años cubrieron tres grandes temas: la defensa del laicismo; la exaltación de las virtudes de las figuras más expresivas de la historiografía liberal, y la cuestión limítrofe, poniendo el énfasis en el conflicto con Chile. Eran editados por la misma LACL u otras editoriales.

Si bien los laicistas no pudieron detener el avance de la Iglesia, lo cierto es que los católicos tampoco lograron obtener todo lo que pretendían, en parte por el accionar de los gremios docentes. Funcionarios católicos propusieron en dos oportunidades derogar la Ley 1420 (1968 y 1979) e implementar una "reforma educativa" (1968) y no lo lograron. Uno de los actores decisivos que frenó estas dos medidas en 1968 fue la CAMYP, junto con otros sindicatos. Durante la última dictadura, los socialistas se dividieron frente a la represión desatada: Bravo fue víctima del terrorismo de Estado en tanto referente de la CTERA y la APDH y fue expulsado de la CAMYP; y los del PSD integraron el gobierno y se quedaron con la conducción de la segunda entidad. Simultáneamente, los dos continuaron criticando toda la política educativa dominada por funcionarios católicos, aunque los últimos se negaron a participar de las huelgas docentes hacia el fin de la dictadura.

En relación con el aumento del presupuesto que denunciaban los laicistas, lo concreto fue que el Estado depositaba con atraso los pagos a las escuelas subsidiadas y llegaban desvalorizados a causa de la inflación. De todos modos, el Estado nunca dejó de realizar los aportes, tal como pedían los laicistas. Otra cuestión que denunciaban era que el sistema privado en su conjunto había crecido en esos años. Es preciso señalar que si bien el número de escuelas privadas aumentó, lo hizo acompañando el crecimiento más general del sistema educativo, y porcentualmente su participación fue relativamente estable en todo el período: el número de establecimientos privados en el nivel primario se mantuvo en el $10 \%$ y en el secundario fue del $43 \%$ aproximadamente ${ }^{75}$.

75 El número de escuelas primarias privadas representaba el $10 \%$ del sistema (2092 escuelas en 1970 y 2048 en 1981), mientras que el número de alumnos primarios sí tuvo un leve aumento: fue del 15,9\% 
Acerca del período que se abrió después de la apertura democrática (19832006), mencionaremos brevemente que los movimientos laicistas continuaron sin poder ejercer una presión más eficaz. La Iglesia siguió teniendo funcionarios aliados y tuvo un protagonismo muy relevante en la redacción de los documentos finales del Congreso Pedagógico Nacional finalizado en 1988. Esos manuscritos fueron en parte, la base para la redacción de la Ley Federal de 1993. Cuando se aprobó, los católicos titularon: "El fin de cien años de laicismo confeso" "76. A partir de esa norma se profundizó la tendencia que habían vislumbrado los laicistas: el Estado neoliberal hizo suyo el argumento que la educación privada era menos costosa que la pública y el sistema privado comenzó a crecer sostenidamente, pero en un contexto diferente. A diferencia del pasado, las clases medias urbanas estaban cada vez más secularizadas y las escuelas católicas recibían a familias que practicaban poco o nada la religión. En medio de este proceso, la Iglesia dijo estar siendo atacada: en el año 2006 dirigentes políticos de convicciones laicistas derogaron la Ley Federal y promulgaron una nueva norma, a la que los representantes eclesiásticos le dedicaron sus más agudas críticas.

\section{Bibliografía}

Altamirano, Carlos. "Estudio preliminar". En Bajo el signo de las masas. Buenos Aires: Sudamericana, 1999.

Arredondo, Adelina y González Villarreal, Roberto. "De la secularización a la laicidad educativa en México", Historia de la educación. Anuario SAHE. Vol. 15, No 2, (2014): 140-167.

(538.582) en 1970 al $18 \%$ en 1981 (720.812). En el nivel medio, el número de establecimientos de enseñanza privada secundaria fue disminuyendo porcentualmente: del 47, $9 \%$ (2062 colegios) en 1970 a 43,7 \% (2163 colegios) en 1981. Lo mismo ocurrió con la matrícula en colegios secundarios privados: fue del 33,1 \% (324.781 alumnos) al 30,3\% (432.521 alumnos). Estos porcentajes podían variar en cada una de las jurisdicciones. Juan Carlos Tedesco, Cecilia Braslavsky y Raúl Carciofi, El proyecto educativo autoritario. Argentina 1976-1982 (Buenos Aires: FLACSO, 1983), 118 y 155.

76 El contexto y las razones del pronunciamiento de esta frase, están en Laura Graciela Rodríguez, "Iglesia y educación en la Argentina durante la segunda mitad del siglo XX", Cadernos de Histórica da Educação, v. 14, No 2, (2015): 263-278. Cabe señalar que la Ley Federal estuvo lejos de imponer la enseñanza católica en las escuelas públicas, pero sí favoreció la expansión del sistema privado. Sin embargo, en ciertas provincias como Salta, nunca se dejó de impartir la materia religión. 
Becerra, Marina. "Intelectuales socialista, Estado y educación en Argentina a principios del siglo XX", Revista Confluencia, Año 3, (2007): 13-29.

Caballero, Gabriela Dalla-Corte. Mocovíes, franciscanos y colonos en la zona chaqueña de Santa Fe (1850-2011). Rosario, Prohistoria, 2012.

Caimari, Lila. Perón y la Iglesia Católica. Religión, Estado y Sociedad en la Argentina. 1943-1955. Buenos Aires: Ariel, 1995.

Di Stefano, Roberto y Zanatta, Loris. Historia de la Iglesia Argentina. Desde la Conquista hasta fines del siglo XX. Buenos Aires: Mondadori, 2000.

Di Stefano, Roberto. "El pacto laico argentino (1880-1920)", Polhis, $\mathrm{N}^{\circ}$ 8, (2011): 80-89, disponible en http://historiapolitica.com/datos/ boletin/polhis8_DiSTEFANO.pdf [consultado 3 de marzo 2012]

Di Stefano, Roberto. "Por una historia de la secularización y de la laicidad en la Argentina", Quinto Sol, Vol. 15, No. 1, (2011): 1-32.

Di Stefano, Roberto. Ovejas negras. Historia de los anticlericales argentinos. Buenos Aires: Sudamericana, 2010.

Ferreyra, Silvana G. Socialismo y antiperonismo: el Partido Socialista Democrático. Transformación partidaria y dinámica política en tiempos de proscripción (Provincia de Buenos Aires, 1955-1966), Tesis Doctorado Interuniversitario en Historia. Mar del Plata: Universidad Nacional de Mar del Plata, 2012.

Galván, María Valeria. El nacionalismo de derecha en la Argentina posperonista. Un cuadro de sus cambios y continuidades en la larga década del sesenta a partir de la lectura del semanario Azul y Blanco (19591969). Rosario: Prohistoria, 2012.

García Sebastiani, Marcela. "El Partido Socialista en la Argentina peronista: oposición y crisis de representación política", Estudios Interdisciplinarios de América Latina y el Caribe, Vol. 13, (2002).

Herrera, Carlos Miguel. "¿La hipótesis de Ghioldi? El socialismo y la caracterización del peronismo (1943-1956)”. En Camarero, Hernán y Herrera, Carlos Miguel (ed.) El Partido Socialista en Argentina. Buenos Aires: Prometeo, 2005, 343-366.

Jannello, Karina. "Las políticas culturales del socialismo argentino bajo la Guerra Fría. Las redes editoriales socialistas y el Congreso por la Libertad de la Cultura", Papeles de Trabajo, año 7, No 12, (2013): 212-247. 
Lida, Miranda. "La Iglesia Católica en las más recientes historiografías de México y Argentina. Religión, modernidad y secularización”, Historia Mexicana, $N^{\circ}$ 4, (2007): 1339-1426.

Lionetti, Lucía. "La educación pública: escenario de conflictos y acuerdos entre católicos y liberales en la Argentina de fines del siglo XIX y comienzos del XX", Anuario de Estudios Americanos, Vol. 63, (2006): 77-106.

Mallimaci, Fortunato. "Catolicismo y militarismo en Argentina (19301983)", Revista de Ciencias Sociales, No 4, (1996): 181-218.

Mallimaci, Fortunato El mito de la Argentina laica. Buenos Aires: Capital Intelectual, 2015.

Martínez Mazzola, Ricardo. "Justo, Korn, Ghioldi. El Partido Socialista y la tradición liberal”, Papeles de trabajo, N 8, (2011): 35-52.

Mauro, Diego. "Procesos de laicización en Santa Fe (Argentina): 18601900. Consideraciones sobre la Argentina liberal y laica”, Revista de Indias, $N^{\circ}$ 261, (2014): 539-560.

Nicoletti, María Andrea. "La congregación salesiana en la Patagonia: civilizar, educar y evangelizar a los indígenas (1880-1934)", Estudios interdisciplinarios de América Latina y el Caribe, Vol. 15, (2004): 71-92.

Pintassilgo, Joaquim. (coord.) Laicidades, Religioes e Educacoa na Europa do Sul no Século XX. Lisboa: FCT, 2013.

Plotkin, Mariano. Mañana es San Perón. Buenos Aires: Ariel, 1993.

Puiggrós, Adriana. Qué pasó en la educación argentina. Buenos Aires: Galerna, 1996.

Rodríguez, Laura Graciela. "Los católicos desarrollistas en Argentina. Educación y planeamiento en los años de 1960”, Diálogos, Vol. 17, $\mathrm{N}^{\circ}$ 1, (2013): 155-184.

Rodríguez, Laura Graciela. "Iglesia y educación en la Argentina durante la segunda mitad del siglo XX", Cadernos de Histórica da Educação, Vol. 14, No 2, (2015): 263-278.

Rodríguez, Laura Graciela. "Las ideas católicas sobre la educación en los años de 1960 y 1970. El caso del Consudec". En Miradas desde la Historia social y la Historia intelectual. América Latina en sus culturas: de los procesos independistas a la globalización. Hugo Cancino et. al. (comp.) Córdoba: Centro de Estudios Históricos Carlos Segretti, 2012, 889-904, e-book. 
Rodríguez, Laura Graciela. Católicos, nacionalistas y políticas educativas durante la última dictadura (1976-1983). Rosario: Prohistoria, 2011.

Schoó, Susana. "Propuestas e iniciativas locales y su incidencia en las políticas nacionales. El papel de los rectores de los colegios nacionales. 1863-1880”, Actas XIV Jornadas Interescuelas/Departamentos de Historia. Mendoza: Universidad Nacional de Cuyo, 2013.

Tedesco, Juan Carlos. Educación y Sociedad en la Argentina (1880-1945). Buenos Aires: Ed. del Solar, 1993.

Tedesco, Juan Carlos; Cecilia Braslavsky, y Raúl Carciofi. El proyecto educativo autoritario. Argentina 1976-1982. Buenos Aires: FLACSO, 1983.

Torres, Germán. "Iglesia católica, educación y laicidad en la historia argentina”, História da Educação, No 18 (2014): 165-185.

Tortti, María Cristina. El "viejo" Partido Socialista y los orígenes de la "nueva" izquierda. Buenos Aires: Prometeo, 2009.

Zanatta, Loris. Del Estado liberal a la nación católica. Bernal: UNQ, 1996.

\section{Fuentes}

\section{Archivo}

Archivo Universidad Popular Alejandro Korn (UPAK).

Archivo Biblioteca Nacional de Maestros.

Publicaciones periódicas.

Consudec (varios números).

La Vanguardia (varios números).

\section{Libros}

Arancibia, Isauro F. "Homenaje a Atilio Torrasa”, Propósitos, No 427, 13 enero 1972.

Astolfi, Adolfo. Historia de la Escuela Normal de Profesores Mariano Acosta. Buenos Aires: Asociación de Exalumnos, 1974.

Bravo, Alfredo P. "La reedición de la Escuela Intermedia”. En La escuela intermedia en debate. Villaverde, Aníbal (coord.) Buenos Aires: Humanitas, 1971, 219-230.

Bravo, Héctor Félix. (comp.) A cien años de la Ley 1420. Buenos Aires: CEAL, 1985. 
Campobassi, José S. La educación primaria desde 1810 hasta la sanción de la Ley Nacional 1420. Buenos Aires: Consejo Nacional de Educación, 1935.

Campobassi, José S. Ley 1420. Buenos Aires: Gure, 1956.

Campobassi, José S. Sarmiento y la Ley 1420. Santa Fe: Universidad Nacional del Litoral, 1960.

Campobassi, José S. Sarmiento: sus ideas sobre religión, educación y laicismo: respuesta a un libro antisarmientista. Buenos Aires: Liga Argentina de Cultura Laica, 1961.

Campobassi, José S. Laicismo y catolicismo en la educación pública argentina. Buenos Aires: Gure, 1961.

Campobassi, José S. Sarmiento y Mitre: hombres de Mayo y Caseros. Buenos Aires: Losada, 1962.

Campobassi, José S. Sarmiento frente a una acusación de traición a la Patria: la cuestión de los límites con Chile y el problema de la Patagonia. Buenos Aires: Liga Argentina de Cultura Laica, 1966.

Campobassi, José S. Sarmiento y su época. Buenos Aires: Losada, 1975.

Campobassi, José S. Sarmiento y la defensa de la Patagonia. Buenos Aires: Liga Argentina de Cultura Laica, 1977.

Campobassi, José S. Nicolás Repetto. Buenos Aires: Editora La Vanguardia, 1980.

Campobassi, José S. Argentina en el Atlántico. Chile en el Pacífico. Buenos Aires: Librería Platero, 1981.

CTERA, Universidad: la 'Misión' del caos y la destrucción. Documento preparado y diagramado por las secretarías de la rama universitaria y de relaciones gremiales de la CTERA y su edición fue costeada con el aporte de los docentes. Buenos Aires: CTERA, 1975.

Furlong, Guillermo. Tradición religiosa en la escuela argentina. Buenos Aires: Ed. Theoria, 1957.

Nigro, Juan Carlos. La lucha de los maestros. Buenos Aires: Confederación de Maestros, 1984.

Torrassa, Atilio E. "La secularización del Estado en la Argentina". En. Transformación de las instituciones públicas y laicidad en Europa occidental”. Editado por Pedro Lamarque Rosario: Ediciones Trabajo, 1968, 5-34. 
Torrassa, Atilio. Filosofía de la educación: grandes figuras de la pedagogía: legislación escolar. Buenos Aires: Edicon, 1965.

Torrassa, Atilio. Mitre, paladín del laicismo. La enseñanza neutral o laica y la enseñanza libre. Buenos Aires: Ediciones de Sarmiento, 1957.

Torrassa, Atilio. Sarmiento y la libertad de enseñanza: un artículo enjundioso no incluido en las obras completas del gran maestro. Buenos Aires: Liga Argentina de Cultura Laica, 1963.

Vázquez, Silvia Andrea y Balduzzi, Juan. De Apóstoles a trabajadores. Luchas por la unidad sindical docente 1957-1973. Buenos Aires: CTERA, 2000.

Para citar este artículo: Rodríguez, Laura Graciela. "Educación, laicismo

210 y socialismo en la Argentina: las organizaciones de maestros y profesores entre 1955 y 1983", Historia Caribe Vol. XII No. 30 (Enero-Junio 2017): 179-210. DOI: http://dx.doi.org/10.15648/hc.30.2016.7 